\title{
Sensitivity of Climate to Changes in NDVI
}

\author{
L. Bounoua, ${ }^{*}$ G. J. Collatz, ${ }^{+}$S. O. Los, ${ }^{\neq}$P. J. Sellers, ${ }^{\otimes}$ \\ D. A. Dazlich, ${ }^{\times}$C. J. Tucker ${ }^{+}$and D. A. Randall ${ }^{\times}$
}

* Department of Meteorology, University of Maryland, College Park, and NASA/GSFC, Biospheric Science Branch, Greenbelt Maryland

+ NASA/GSFC, Biospheric Science Branch, Greenbelt Maryland

F Science Systems and Applications Inc., NASA/GSFC, Biospheric Science Branch, Greenbelt Maryland

${ }^{\otimes}$ NASA/JSC, Houston, Texas

${ }^{\times}$Department of Atmospheric Sciences, Colorado State University Fort Collins, Colorado 


\begin{abstract}
The sensitivity of global and regional climate to changes in vegetation density is investigated using a coupled biosphere-atmosphere model. The magnitude of the vegetation changes and their spatial distribution are based on natural decadal variability of the normalized difference vegetation index (ndvi). Different scenarios using maximum and minimum vegetation cover were derived from satellite records spanning the period 1982-1990.
\end{abstract}

Albedo decreased in the northern latitudes and increased in the tropics with increased ndvi. The increase in vegetation density revealed that the vegetation's physiological response was constrained by the limits of the available water resources. The difference between the maximum and minimum vegetation scenarios resulted in a $46 \%$ increase in absorbed visible solar radiation and a similar increase in gross photosynthetic $\mathrm{CO}_{2}$ uptake on a global annual basis. This caused the canopy transpiration and interception fluxes to increase, and reduced those from the soil. The redistribution of the surface energy fluxes substantially reduced the Bowen ratio during the growing season, resulting in cooler and moister near-surface climate, except when soil moisture was limiting. 
Important effects of increased vegetation on climate are :

- A cooling of about $1.8 \mathrm{~K}$ in the northern latitudes during the growing season and a slight warming during the winter, which is primarily due to the masking of high albedo of snow by a denser canopy.

- A year round cooling of $0.8 \mathrm{~K}$ in the tropics.

These results suggest that increases in vegetation density could partially compensate for parallel increases in greenhouse warming .

Increasing vegetation density globally caused both evapotranspiration and precipitation to increase. Evapotranspiration, however increased more than precipitation resulting in a global soil-water deficit of about $15 \%$.

A spectral analysis on the simulated results showed that changes in the state of vegetation could affect the low-frequency modes of the precipitation distribution and might reduce its low frequency variability in the tropics while increasing it in northern latitudes. 


\section{Introduction}

Despite significant progress in the study of land-surface processes over the last 20 years, lack of understanding of land-biosphere-atmosphere interactions still constitutes a major obstacle in climate modeling. It is widely agreed that the energy exchanges at the land-atmosphere interface largely determine the climate and its variations (Chahine , 1992). However, the wide range of spatio-temporal scales involved in land surface processes and the many difficult-to-measure parameters that characterize the surface properties make it difficult to capture the essence of the physics in a simple model. The relative partitioning of the total radiative flux reaching the earth's surface into absorbed, sensible, latent and emitted components depends strongly on the state of the land surface: its albedo, aerodynamic roughness and the availability of soil moisture, all of which are tempered by the vegetation cover.

Land evapotranspiration feeds back on cloud formation and precipitation altering thus the total incoming radiation and creating a strong coupling between the land surface and the atmosphere. The problem becomes even more complex when the terrestrial vegetation is considered. Vegetation is a major pathway by which soil water is transferred to the atmosphere and, therefore, has the potential to respond to and affect the land hydrology, a process which may be affected by short- term perturbations such 
synoptic-scale storms and by long-term perturbations such as droughts. It becomes evident therefore that a perturbation to any physical component of the land-biosphere-atmosphere system can propagate to other components causing a wide range of responses scaling from millimeters and seconds for photosynthesis to many kilometers and multiple years for climate .

The interactions between the biosphere and the atmosphere have been the focus of climate sensitivity studies for the last twenty years and have focused on 3 aspects of land surface state, namely albedo, ground wetness and roughness. The bio-geophysical feedback mechanism postulated by Charney ( 1975,1977$)$, in which lack of rainfall leads to maintenance of aridity, may be linked to vegetation in the sense that a change in the vegetation density is associated with a change in albedo. Since Charney's papers, several studies have been carried out to assess the influence of land surface albedo and its effect on climate (e.g., Chervin 1979; Carson and Sangster 1981: Sud and Fennessy 1982; Laval and Picon 1986 ). After the pioneering work of Manabe (1975), which addressed the interaction between the hydrological cycle and climate, the influence of soil wetness on atmospheric circulation and climate has been extensively examined (e.g., Walker and Rowntree 1977; Shukla and Mintz 1982; Rind 1982; Rowntree and Bolton 1983; Yeh et al. 1984; Sud and Mollod 1988; Rowell and Blondin 1990; 
Gash et al. 1991; Bounoua and Krishnamurti 1993 (a,b), and others ). The effect of soil moisture on climate was, however, best illustrated by Shukla and Mintz (1982) who simulated the global climate response to a drastic change in soil water over continents. Although idealized, their experiments bracketed the effects of surface water evaporation on the atmospheric general circulation between two extreme conditions. Surface roughness has also been shown to play an important role in land surface processes (Deardorf 1972; Sud and Smith 1984 ). Changes in the surface roughness affect the turbulent exchanges and can substantially impact the fluxes of heat, moisture and momentum. All these studies were designed to address the response of a particular component of the land-surface processes, but most of them did not account for the coupling among the different land-surface elements. For instance, an increase in soil moisture was not associated with a decrease in albedo nor was the albedo anomaly accompanied by a change in the roughness length as one would expect in the real world. In these studies, albedo, soil moisture and roughness length were independently specified at each grid point of the general circulation model (GCM). Furthermore, the models used to carry out these investigations did not include the physiological response of the vegetation, which has been shown to play an 
important role in the modulation of the land surface processes (Sellers et al. 1996a ; Bounoua et al. 1999).

More recent deforestation studies using biophysically based land surface models (e.g., Nobre et al. 1991; Xue and Shukla 1993; Sud et al. 1996 ) showed how degradation of regional vegetation can affect climate. In their numerical simulations, Nobre et al., (1991) found that changing the Amazonian tropical forest into pastures led to a local decrease of $2.5 \%$ in precipitation, and an increase in the mean surface temperature of about $2.5 \mathrm{~K}$. Similarly, Xue and Shukla (1993) showed that the desiccation of the land surface over West Africa resulted in a significant reduction of local precipitation.

Several other modeling groups have investigated the effects of vegetation on regional climate (e.g., Xue et al. 1996; Pielke et al. 1997; Bonan 1992, 1997). In addition to changes in the vegetation density, these studies also included changes in vegetation type and related parameters. Bonan (1997) studied the effects of land use on the climate of the United States. He showed that replacing the natural vegetation by modern vegetation over the United States was characterized by a cooling of $1 \mathrm{~K}$ over the Eastern United States and a warming of $1 \mathrm{~K}$ over the western part during spring. His simulations also showed a warming of about $2 \mathrm{~K}$ during summer over large regions of the Central United States. 
The sensitivity of a general circulation model to global changes in leaf area index (lai) was examined by Chase et al. ( 1996). They compared climate simulations using a distribution of maximum lai derived from satellite data as a control and a distribution of potential lai assumed to be in equilibrium with current climate hydrology. They showed that decreasing lai globally resulted in decreasing the surface latent heat flux and increasing the sensible heat flux during January and July.

In the present study, we use the Simple Biosphere model, SiB2 (Sellers et al. 1996b) coupled to the Colorado State University general circulation model (Randall et al. 1996) to examine the sensitivity of global and regional climate to observed changes in vegetation density (ndvi), derived from multi-year satellite observations.

\section{Model and data}

\section{II-1 The Model}

$\mathrm{SiB} 2$ is a biophysically based land-surface model that includes a stomatal conductancephotosynthesis sub-model which spatial and temporal vegetation characteristics are driven by satellite data .

In SiB2, the vegetation distribution (DeFries and Townshend 1994; Collatz et. al. 1998) 
as well as its spatial and temporal phenology are described using global satellite observations ( Sellers et al. 1996b ). Monthly average values of ndvi are assigned to the middle of the month. A linear interpolation between these values is performed daily so that the time evolution of the ndvi is smooth. The normalized difference vegetation index (ndvi) is used to calculate monthly fields of the fraction of photosynthetically active radiation absorbed by the green leaves of the canopy (fpar) and the leaf area index (lai). Fpar is strongly correlated to the ndvi (Sellers 1985) and is used directly in an integrated canopy photosynthesis-conductance model (Collatz et al. 1991, 1992) to calculate the photosynthesis and transpiration rates (Sellers et al. 1987, 1992). In our model fpar is prescribed from satellite observations, it then affects the surface energy balance but does not respond to it.

Vegetation physiology also responds to climate conditions, temperature and water. Therefore a perturbation of the land-biosphere-atmosphere system may result in a positive or negative feedback, depending on the intensity of the perturbation imposed. For example, a modest increase (decrease) in fpar is expected to produce more (fewer) leaves and consequently to drive cooling (warming) through increased transpiration. If the perturbation is stronger however, plants can be water-stressed, and an increase in fpar beyond a certain limit will cause the stomates to close and so result in warming. 
Furthermore, a change in vegetation density affects the surface roughness and so alters the turbulent exchanges of energy, water and momentum at the land-atmosphereinterface. The photosynthetic uptake of $\mathrm{CO} 2$ from the atmosphere is coupled to a water loss from the leaf interior and from soil water through the stomates in a way that is consistent with observations and ecological theory of resources use efficiency ( See Cowan, 1986). The capacity of vegetation to convert soil moisture into latent heat flux is determined by fpar and stomatal conductance. The former is prescribed and derived from global ndvi data sets while the latter depends on atmospheric conditions and the amount of water available in the model's root-zone layer; thus establishing a strong coupling between the atmospheric forcing and the soil hydrology. The satellite derived fpar is converted to leaf area index (lai) which is used in a radiative transfer two-stream model (Sellers et al. 1996b) to calculate albedo and radiation partition between the canopy and ground. The surface roughness length also depends on the lai. The land-surface model coupled to the GCM responds to the precipitation, the shortwave and longwave direct and diffuse components of downwelling radiation, the temperature and the wind speed at the model's lowest atmospheric layer. The land-surface model returns to the GCM four components of the latent heat, namely the ground interception loss, the soil evaporation, canopy interception loss and canopy 
transpiration. It also returns the soil and canopy sensible heat fluxes, the reflected and emitted radiation fluxes and the photosynthetic carbon flux.

The SiB2 hydrological model distributes the incoming precipitation into a canopy interception component and a throughfall component. The canopy interception can either evaporate at the potential rate or contribute to the throughfall when the canopy's holding capacity is exceeded. The combination of direct throughfall and water dripping from the canopy is added to the ground liquid water store. There, the water can either evaporate or infiltrate into a shallow $(2 \mathrm{~cm})$ surface layer if the ground storage capacity is exceeded. If the infiltration rate is in excess of the infiltration capacity of the soil, the excess water contributes to surface runoff. Similarly, water from the surface layer can either evaporate or infiltrate into the root zone layer from which it can flow up into the surface layer, infiltrate into the deep layer, contribute to runoff, or be used by plants for transpiration. From the deep soil layer, water can diffuse up to the root layer or contributes to runoff through drainage .

The physical parameterization in the CSU GCM includes a radiative transfer scheme which computes the solar and terrestrial radiation following Hardvardhan et al. (1987). The radiative transfers calculations are invoked every simulated hour. The GCM includes an improved Arakawa-Schubert cumulus parameterization scheme as 
described by Randall and Pan (1993) and a detailed cloud microphysics scheme

(Fowler et al. 1996; Fowler and Randall 1996 (a,b).

A comprehensive description of the CSU GCM is given by Randall et al. (1996)

\section{II-2 Data and Experiments}

The data used in this study are provided from a unique compilation of a multi-year (1982-1990) satellite observations developed at NASA's Goddard Space Flight Center. This data set known as the FASIR-ndvi, consists of a global monthly $1^{\circ} \times 1^{\circ}$ ndvi obtained from AVHRR and processed for consistency to account for data anomalies through a Fourier adjustment (FA), solar zenith angle correction (S), data dropout in cold land points (I) and persistent tropical cloud cover (R). The original ndvi data were corrected for volcanic aerosols, sensor degradation and cloud effects (Sellers et al. 1996c; Los 1998). The use of this data set in SiB2 has introduced a spatial and temporal coherence in the description of global vegetation phenology, an important element in the land-biosphere-atmosphere energy and carbon exchanges.

From this data set we have constructed three subsets that correspond to scenarios with minimum, maximum and average ndvi. For a particular month, each grid cell was assigned the absolute minimum ndvi value observed over the 9 year period. A similar 
scenario was obtained using the maximum ndvi. The average ndvi scenario consisted of taking, for a given month and grid cell, the average ndvi obtained from the 9 year data set. The same vegetation classification was used for the entire period (Plate 1).

Figures 1. a, b and c show the seasonal variation of the ndvi for the 3 scenarios over the northern latitudes, tropics and all land, respectively. Although the absolute difference between the maximum and minimum ndvi is quite large in the northern latitudes during winter, where the lowest ndvi values were observed, its effect is expected to be small because of low solar radiation during this time of the year. The overall effect of increased ndvi should, therefore, dominate during the growing season when an increase in ndvi of about 0.1 between the maximum and minimum scenarios is detected in the observed data set. This absolute difference represents a relative increase of about $17 \%$ during July and is much smaller than the amplitude of the seasonal cycle. Typically over a season, fpar varies between 0.2 and 0.7 for an evergreen forest and between 0.3 and 0.7 for a deciduous forest. The global distribution of the annual mean difference between the maximum and minimum ndvi scenarios is presented in fig. 1d.

Global $1^{\circ} \times 1^{\circ}$ ndvi data corresponding to the three scenarios were pre-processed off-line to produce monthly fields of fpar, lai, vegetation greenness fraction as well as snow free albedo and roughness on a 7.2 by 9.0 degrees grid. These were then used as 
boundary conditions for the model to run 315 -year simulations in order to assess the sensitivity of global and regional climate to changes in the state of the terrestrial vegetation. Fixed climatological sea surface temperatures were used in all three simulations so that the results isolate the land-surface effects. The model runs were conducted at $7.2^{\circ}$ by $9.0^{\circ}$ horizontal resolution with nine layers.

These scenarios are more extreme than the interannual variability observed during the 9 year period. It is plausible, however that over decades to centuries changes of this magnitude could occur.

Of particular interest to us is the sensitivity of global and regional climate to changes in the physical state of the vegetation and comparison of model-generated results. In this context and for simplicity, our analysis is put in the framework of differences between the maximum and minimum simulations rather than absolute simulation accuracy.

\section{Results and Discussion}

The analysis of the global simulations was conducted by latitude bands. The results are summarized for : a tropical band(14S-14N), a mid-latitude band(28.8N-50.4N), a northern latitude band(50.4N-72N), and the entire land surface. Because the middle latitudes and the northern latitudes regions have similar results, the discussion focuses 
on the tropical and the northern-latitude bands and for all land points including bare soil. These two latitude bands present the maximum change in ndvi over the 9 year period. Except for fpar, our results are presented as averages over the last five years of each simulation when soil moisture and climate come very close to equilibrium. In the following analysis, the active growing season is defined as the period during which photosynthesis actually occurs and vegetation vegetation is not stressed.

\section{III-1 Albedo}

The amount of vegetation affects surface albedo, an important factor in the determination of the net solar radiation absorbed at the surface. An increase in vegetation density (ndvi) is generally expected to reduce albedo because of the strong absorptance in the PAR region of the solar spectrum. This direct relationship between surface albedo and vegetation density becomes more complex when the soil background, leaf and canopy reflectance properties are considered (e.g., Bonan 1997). If the canopy is brighter than the soil background, an increase in vegetation density leads to an increase in the surface albedo. In the presence of snow, however, an increase in the vegetation density is always associated with a reduction of surface albedo. In our model, soil background and leaf reflectance are externally prescribed for 
each soil and vegetation type, respectively ( Sellers et al. 1996c).

Table 1 shows the changes in fpar and albedo caused by increasing the ndvi from the minimum to the maximum scenario. The increase in ndvi has increased fpar for both latitude bands, with a maximum relative increase during January. The relative increase in fpar was higher at northern latitudes than in the tropics although the absolute differences were slightly larger in the tropics.

Albedo increased in the tropics and decreased in the northern latitudes. Overall the increase in the tropics was less than the decrease in the northern latitudes where albedo went down by about $9 \%$ and $6 \%$ during January and July, respectively. The decrease in surface albedo in the northern latitudes is in line with previous studies (Bonan 1997). During July, the decrease in snow free albedo is primarily due to soil and leaf reflectance properties and vegetation cover fraction whereas the large decrease in January includes the masking of high albedo of snow by a denser vegetation. In our model, canopy reflectance is higher than soil reflectance for tropical vegetation, therefore an increase in vegetation density increased albedo in the tropical regions. Though not large enough to significantly alter the surface energy balance at a global scale, changes in total albedo do show how a perturbation to the canopy morphology can affect the surface reflectance and thus its energy budget. 


\section{III-2 Canopy conductance and photosynthesis}

As expected, the increase in fpar had a significant impact on the plants' physiological activity. In the tropics, where the seasonality is weaker, the maximum-ndvi scenario produced year around increase in fpar of about 0.2 (Fig. 2 a,b). This boosted the plants' net photosynthesis rate and increased canopy conductance. For approximately the same increase in fpar, the July carbon assimilation and transpiration increases were about half those simulated in January. This is because increasing fpar in July was not associated with a sufficient increase in rainfall. The soil water was then reduced to the point where water stress in the model limited the expected proportional increase in carbon assimilation and conductance ( Sellers et al. 1996b ). In other words, an increase in fpar by itself, no matter how large it is, can only drive the plants' physiological activity within the limits of their water resources, which are determined by climate conditions since soil properties did not change. In the real world, an increase in vegetation density and consequently in fpar can happen only where climate conditions, especially water resources, allow it. The increase in water stress in the tropics was most apparent during July and was reflected in the global means (Fig.2.e,f). An overall annual increase in the water stress of about $54 \%$ was simulated over vegetated land, mostly in the tropics. This suggests that the total mass of leaves in the canopy 
cannot be sustained by the amount of root zone water simulated by the model and should therefore be reduced. This effect is not included in our model in which the seasonal cycle of the vegetation density is externally prescribed from satellite observations.

In the northern latitudes, where water was less limiting, the increase in fpar was directly reflected in the simulated change of the photosynthetic rate during July (Fig.2c), while during January when the plants' physiological activity is completely shut down by cold winter temperatures, the increase in fpar had no effect on the carbon assimilation rate or stomatal conductance (Fig $2 \mathrm{~d}$ ). Thus, in the northern latitudes, the effect of increased vegetation density on the vegetation physiological activity appears qualitatively similar to that of increasing the length of the growing season. In fact, the increase in ndvi , as is the case in our maximum scenario simulation, results in intensifying the vigor of the physiological activity during the whole growing season. An increase in the length of the growing season, on the other hand, would keep the vegetation active for a longer time without necessarily increasing its intensity. These two effects are believed to have similar impacts on the vegetation productivity integrated over the entire growing season.

Except for the tropics, where our maximum fpar scenario may have slightly 
overestimated the vegetation density during the northern summer, these results may well represent the maximum expected physiological effects of an eventual increase in the length of the vegetation active growing season and its impact on climate. Over all land, an increase of about $40 \%$ in fpar during the month of July ( Table 1) led to a global increase of $38 \%$ in the carbon assimilation rate, of which the northern latitudes vegetation accounted for about $52 \%$ versus only $27 \%$ for the tropical vegetation (Table 2). It is worth noting however, that these differences are computed using the minimum scenario as the control and should be approximately halved had the control been the average ndvi scenario. In these simulations the ndvi forcing is global. However, the simulated climate indicates that an increase in vegetation density of this magnitude is sustainable only in the northern latitudes. These results are in line with previous studies which observed that the maximum increase in plant's activity during the period 1982 and 1990 took place in the northern latitudes between approximately 45 and $70 \mathrm{~N}$ (Myeneni et al. 1997).

\section{III-3 Energy Budget}

Figure 3 shows changes in the surface energy balance averaged over the two latitude bands as well as over all land points during the months of January and July. A considerable trade off between the different components of the surface energy budget was 
observed between the maximum and minimum ndvi scenarios. Globally, the net absorbed shortwave radiation has decreased as a result of increasing ndvi, and this is to a large extent due to a decrease in the incident shortwave radiation since the albedo change was small. This effect was more pronounced in the northern latitudes during July. In the tropics, the increase in ndvi was associated with an increase in the total latent heat flux and a decrease in the sensible heat flux. This change was more evident during January (Fig.3b). During the month of July, the tropical vegetation experienced moderate water stress (see Fig.2) and the latent and sensible heat fluxes were about equally traded between the canopy and the soil (Fig.3a). There, the net absorbed radiation at the top of the canopy did not show significant changes, but, the increase in the mass of leaves in the canopy, associated with increased ndvi, increased the energy absorbed by the canopy and so increased the plants' water demand. This limited the increase in canopy conductance and as a result, a considerable portion of the radiative energy went into heating the canopy rather than extracting water through transpiration. On the other hand, in January when the vegetation was less water stressed, the canopy transpiration flux increased by about $12 \mathrm{~W} \mathrm{~m}^{-2}$ versus an increase of only $3 \mathrm{~W} \mathrm{~m}^{-2}$ for the canopy sensible heat flux.

In the northern latitudes, the month of July was characterized by more cloudiness and 
rainfall. In these regions, the increase in ndvi was so important that the soil sensible heat flux decrease was about three times larger than the increase in the canopy sensible heat, and the increase in the transpiration rate was about twice that of the tropics (Fig.3c). The canopy components of the latent heat flux increased, and the ground evaporation and interception loss decreased, as a result of increased canopy coverage. The increase in fpar did not significantly affect the net energy absorbed by the surface at these latitudes, but substantially decreased the Bowen ratio during the growing season. The increase in evapotranspiration at the expense of sensible heating produced a cooler and moister planetary boundary layer, since the total energy remained essentially constant.

Because of the different responses of vegetation to climate, the increase in vegetation density had different regional and seasonal effects. In the northern latitudes, the increase in ndvi had no effect on the plants' physiology during winter, but reduced the albedo and increased the incident shortwave radiation, both of which contributed to increase the net shortwave energy absorbed at the surface by about $\left(1 \mathrm{~W} \mathrm{~m}^{-2}\right)$. Furthermore, a relatively small amount of snow was added to the canopy as ndvi increased (not shown). This reduced the canopy sensible heat and boosted the soil sensible heat flux by about the same amount. The latent heat flux components did not exhibit significant 
variations during winter. On the other hand, a feedback was developed between the vegetation and climate during the summer time when the increase in ndvi led to more evaporation resulting in cooler and wetter atmospheric surface conditions. Again this feedback suggests that the northern latitudes hydrological cycle is able to sustain the prescribed increase in vegetation. Similar results were obtained for the tropics in January. However, during the month of July, because the model did not produce enough rain over most of the southern Amazonian forest, the increase in evaporation from the canopy was smaller than that simulated for January. Globally, the increase in ndvi resulted in increasing the latent and sensible heat fluxes from the canopy while decreasing those from the soil. Canopy transpiration underwent the largest increase, followed by canopy interception.

\section{III-4 Temperature}

The overall effect of increasing ndvi showed interesting regional effects on the surface air temperature as illustrated in Table 3 . The increase in vegetation density resulted in a total annual mean cooling of about $0.8 \mathrm{~K}$ in the tropics. This cooling was particularly important during the month of January. The water limitation simulated during the month of July in the tropics resulted in less transpiration and therefore led to a cooling 
that is about $0.3 \mathrm{~K}$ weaker than that simulated during January. A striking result, however, is that the increase in the ndvi resulted in cooling the air temperature by about $1.8 \mathrm{~K}$ in the northern latitudes during July, while it slightly increased it during January. The winter warming is primarily due to the masking of the high albedo of snow, allowing for more absorption of solar energy. This albedo effect is in agreement with results obtained by Bonan (1997), but is slightly smaller in magnitude. This is probably due to the fact that Bonan's (1997) study included changes in vegetation type going from short (crops) to tall (forests) vegetation, whereas the current simulations kept the vegetation type invariant but increased its density.

Globally, the land surface air temperature decreased by about $1 \mathrm{~K}$ in July and by about $0.4 \mathrm{~K}$ in January. Assuming the minimum and maximum scenarios represent extreme variations around a mean, one can expect the fluctuations in vegetation density to impact surface temperature by about $+/-0.5 \mathrm{~K}$ during the northern hemisphere summer and by only $+/-0.2 \mathrm{~K}$ during the winter with these feedbacks having the same sign and therefore amplifying the causative droughts and/or temperature anomalies .

The seasonal variation of the temperature differences between the maximum and minimum ndvi scenarios for the northern latitudes band is shown in Fig.4. There, our simulations show a gradual increase in surface air temperature during the winter season 
with a maximum warming of about $1 \mathrm{~K}$ during the month of March. After that, the temperature exhibits a gradual decrease, reaching a maximum cooling of about $1.8 \mathrm{~K}$ during the peak of the growing season. The implications are two-fold. First, this result suggests that warmer winter and pre-spring temperatures are a precursor to a strong active growing season. In our model, the growing season is controlled by a low temperature stress factor, a prescribed vegetation type dependent parameter ( Sellers et al. 1996c). If the simulated temperature is warmer than the low temperature stress factor in early sping, the vegetation starts its physiological activity earlier, resulting thus in a longer active growing season. This is especially true for northern latitudes evergreen and mixed forests where low temperatures are the only factors inhibiting photosynthesis during winter. On the other hand, it clearly illustrates the role of the seasonality of the northern-latitude vegetation in the control of the local climate. In fact, the effects of the regular cycle of increased solar radiation from winter to summer in the northern latitudes may be divided into two periods. During the the first period between winter and spring, the increase in solar radiation increases the surface temperature and sets adequate climate conditions for vegetation growth. During the second period, as the vegetation becomes physiologically active during spring to summer, it 
acts to counterbalance the radiative warming through its transpiration, creating thus a negative feedback. These simulated results are in agreement with temperature observations (Piper and Stuart 1996 ) and are consistent with the hypothesis that warmer temperatures have promoted increases in biospheric activity in extra-tropical regions, as inferred from atmospheric CO2 measurements (Keeling et al. 1996; Chapin et al.1996). This could have important impacts on climate. For instance, the daily minimum temperature is expected to progressively increase with the increase in radiation because the vegetation is not active at night, but the daily maximum will increase in phase with it only as long as the vegetation is dormant, i.e. during winter. During spring, after the leafing-out of the vegetation, the increase in the daily-maximum temperature will be limited by plants' transpirational cooling, as shown in Fig.(4). Consequently, the daily mean temperature may continue to rise from winter to summer, but the amplitude of the diurnal temperature range (dtr) may only increase from winter to spring. After that, the dtr levels-off or even declines with the start of the vegetation physiological activity ( see Schwartz 1996; Collatz et al. 1999). This suggests that in the case of a radiative forcing, regardless of its causes, the northern latitude vegetated regions may experience warmer nighttime temperatures and normal or slightly cooler daytime temperatures as a result of the vegetation's diurnal cycle ( see Bounoua et al. 1999). 
Similarly, winters may be warmer and summers slightly cooler due to the seasonal cycle of the vegetation. However, if the radiative forcing is strong enough to bring the vegetation to its physiological limits, the vegetation is then expected to reduce its activity. In our model, this translates to a reduction in stomatal conductance which causes an increase in the daytime temperature. The daily temperature range is expected to increase under these circumstances. Among other factors affecting the daily temperature extremes, such as shortwave and longwave radiation, cloudiness and aerosols (see Karl et al. 1991; Hansen et al. 1995 ) our simulations show that through its diurnal and seasonal cycles, the vegetation can also play an important role in the modulation of the diurnal and seasonal temperature ranges.

The July zonally-averaged air temperature difference between the two scenarios shows an increased cooling following the natural vegetation gradient between the middle latitudes and around $55 \mathrm{~N}$ where a maximum cooling of about $2 \mathrm{~K}$ was simulated ( Fig. 5). Beyond that latitude, the temperature decreased by about $1 \mathrm{~K}$. During January, the meridional distribution of the temperature difference revealed the strongest cooling in the tropics and a warming of up to $1 \mathrm{~K}$ in the northern latitudes above $60 \mathrm{~N}$. The subtropics and middle latitude regions experienced a cooling of less than $0.5 \mathrm{~K}$.

The global distribution of the mean annual temperature difference is shown in Fig.(6) . 
These differences are based on the last five years of each simulation. The problem of separating the signal due to the prescribed forcing from the inherent model variability using Student's t-test was discussed by Chervin and Schneider (1976). At 95\% confidence limit, the chances that the simulated differences could be accounted for by the natural variability of the coupled model are only $5 \%$. The simulated results show a widespread cooling of the near surface air temperature over the continents, with major forests acting as particularly strong heat sinks. This cooling reflects the increase in surface latent heat flux in areas where ndvi increased (see Fig. $1 \mathrm{~d}$ ). The annual mean warming simulated in the northern latitudes is not statistically significant over northern Europe but shows a spatially coherent, statistically significant pattern over Eastern Canada. At these latitudes, the variability in climate is high especially in winter and can easily mask the effect of increased ndvi.

Our simulations show that the feedback mechanisms working between the vegetation and climate are important elements to consider in the interpretation of climate change results simulated by various climate models. For example, the results produced by various climate models indicate that the global-mean surface temperature could increase by up to $4.5 \mathrm{~K}$ in response to a doubling of atmospheric CO2 ( IPCC, 1990, 1995). In most cases, the interactions between the physiological effects and climate 
were ignored. When the same scenario was simulated using biophysically-realistic coupled biosphere-atmosphere climate models, the global temperature increase was only about 2.6 K ( see Pollard and Thompson 1995; Henderson-Sellers et al. 1995; Sellers et al. 1996a). On the other hand, the model proposed by Charney et al. (1975, 1977) according to which a positive albedo anomaly will amplify itself, appears to be valid, only if the physiological component of the vegetation is not considered. In fact, except for places where leaf reflectance is higher than the soil background reflectance, a decrease in vegetation density leads to an increase in albedo and consequently decreases the net shortwave radiation absorbed at the surface. At the same time however it saves ground water and reduces the soil moisture stress on vegetation. This leads to a smaller but less stressed canopy with reduced stomatal resistance to water transfer, and generates a negative feedback to oppose the original albedo anomaly. In other words, the integral canopy conductance of a non-stressed canopy with fewer leaves would be equivalent to that of a denser but stressed canopy. In this context, a natural drought in the semi-arid regions may result in decreasing canopy leaves and increasing albedo. The increase in the incident shortwave radiation due to lack of cloudiness is practically balanced by the increased albedo and the outgoing longwave radiation from a warmer surface, so that the net radiation absorbed at the surface 
remains almost unchanged. The partitioning of the surface energy fluxes may, however, favor the canopy transpiration in the absence of soil moisture stress, and may increase the ground evaporation because more energy reaches the ground. This is believed to maintain about the same Bowen ratio as in the previously vegetated surface and to allow the vegetation to adjust to the drought until another natural climate anomaly reverses the cycle. While this proposed model may help to explain the persistence of vegetation during short anomalous climate events, it is not necessarily applicable to a drastic change such as an anthropogenic deforestation.

\section{III-5 Land-Surface Hydrology}

In these simulations, vegetation generally produced about $44 \%$ of the total evapotranspiration from the canopy transpiration, and about $24 \%$ from the soil evaporation. The canopy and soil interception components accounted for about $16 \%$ each. Changing ndvi globally caused significant changes in the hydrological fluxes and storage over land, and illustrates the negative feedback between evapotranspiration and soil moisture caused by the physiological responses to water stress.

Table 4 shows differences between the maximum and minimum simulations for the various components of the hydrological cycle. In the tropics, the annual hydrological budget shows a strong imbalance between precipitation and evapotranspiration. The 
evaporation went up by about $4.8 \mathrm{~mm} /$ month while the increase in precipitation was only $0.2 \mathrm{~mm} /$ month. This resulted in a significant reduction in runoff. The soil-water deficit was more important during July, although the increase in precipitation almost matched the increase in evaporation. In the northern latitudes, the evaporation rates increased by only $0.2 \mathrm{~mm} /$ month in January, and this was largely compensated for by an increase in precipitation, which caused a surplus of soil water and increased the runoff. During the vegetation active season, the total water deficit was relatively small ( $0.9 \mathrm{~mm} / \mathrm{month})$. Over all land, the increase in ndvi increased both the evapotranspiration and the precipitation. The evaporation, however, went up more than the precipitation, resulting in a global year round soil water content reduction and important inter-layer water transfers.

Figure 7 shows the variations in the monthly mean precipitation rates and the water content in the three soil layers as simulated by the model in the tropics and northern latitudes. The range of the precipitation anomalies is larger in the tropics than in the northern latitudes ( Fig.7ab). In both regions, however, the precipitation anomalies are significantly dampened as they make their way through the hydrological reservoirs. This is due to the storage associated with each soil layer. In SiB2, the surface layer has a uniform shallow depth of $2 \mathrm{~cm}$. Because of its small inertia, the soil water content in 
this layer responds almost instantaneously to precipitation anomalies ( Fig. 7cd). The root-zone depth is specified to be about $1.5 \mathrm{~m}$ for both the tropical and the boreal forests, while the third layer is about $2 \mathrm{~m}$ and $0.5 \mathrm{~m}$ deep for the tropical forest and the northern vegetation, respectively.

A cross-correlation analysis of the differences between the precipitation generated by the two simulations (maximum - minimum) and the soil moisture in the three soil water stores revealed no phase-lag between the precipitation and the surface layer water content variations for both latitude bands. On the other hand, for both regions, the root zone layer water store responded to the precipitation anomalies with about 1 month delay, while the deep layer water variations lagged the precipitation anomalies by 1 month in northern latitudes and about 2 months in the tropics. These results indicate that soil moisture inertia at the land-surface boundary plays an important role in the land-atmosphere interactions, acting as a low-pass filter to transform high frequency atmospheric variability into low frequency hydrological anomalies (see Entekhabi and Rodriguez-Iturbe, 1993). Since in SiB2, the root zone water exerts an influence on stomatal control, a soil moisture anomaly in that layer, produced by a precipitation anomaly, could be persistent. 
Figure 8 shows the sensitivity of the global soil water stores to changes in ndvi during July. The upper surface, the ground and the canopy water content increased, but the root zone and the deep soil layer stores decreased. The decrease from the root zone was expected as the increase in ndvi led to more transpiration, which extracts water only from that layer. This caused significant inter-layers water transfers to compensate for the water outflow from the root zone. The flux of water from the surface to the root layer increased while that flowing out from the root layer to the deep layer decreased. As a consequence, the drainage from the deep layer decreased.

Globally, there is a net ground water deficit and a gain in the surface and canopy water stores during July. The increase in ndvi has altered the recycling of the precipitation. By increasing the canopy interception and transpiration rates, more water resides in the atmosphere than in the ground. Interception by the canopy may be overestimated in this and other studies, and reducing it would increase the soil moisture and the transpiration ( Scott et al. 1995). It took several years of integration for the total soil moisture to adjust to the ndvi changes. In fact, in the tropics there continues to be a decreasing (increasing) trend in the maximum (minimum) run even over the last 5 years ( Fig. 9). 
The ndvi perturbation that we imposed changed the total soil moisture by almost as much as the amplitude of the seasonal cycle in the tropics. In the northern latitudes, the variations were less important. This had important effects on the precipitation's temporal distribution. Figure 10 shows the amplitude of the power spectrum of the monthly mean precipitation rates for both simulations. In the tropics, both simulations have strong annual and semiannual cycles. The maximum ndvi scenario significantly reduced the amplitude of the power spectrum at both 12 and 6 month time scales, while it slightly increased it at higher frequencies (around 4 months ). On the other hand, the maximum ndvi scenario had significantly increased the power of the annual cycle in the northern latitudes. This shows how changes in the state of the biosphere could affect the low-frequency modes of the precipitation's distribution through changes in the soil moisture and atmospheric dynamics.

\section{Concluding Remarks}

A general circulation model coupled to a land surface model is used to investigate the sensitivity of global and regional climate to an increase in the vegetation density.

The increase in ndvi resulted in decreasing the surface albedo in the northern latitudes and increasing it in the tropics. The decrease in the northern latitudes was more 
important than the increase in the tropics.

The canopy physiological response to increased vegetation was limited by the available water resources and revealed that the amount of vegetation prescribed in our maximum scenario could not be sustained by the simulated climate in the tropics. In the northern latitudes, the increase in fpar was reflected in the more-than-proportional increase in carbon assimilation and conductance during the growing season and had no effect during winter.

The increase in vegetation density substantially reduced the Bowen ratio during the growing season, resulting in a cooler and moister near-surface climate. In the tropics, the simulated cooling was about $0.5 \mathrm{~K}$ and $0.8 \mathrm{~K}$ for January and July, respectively. The northern latitudes' surface temperature decreased by about $1.8 \mathrm{~K}$ during July and experienced a small increase during January.

The diurnal and seasonal cycles in vegetation activity are shown to play a role in determining the daily temperature range.

Globally, the increase in ndvi increased both the evapotranspiration and the precipitation. The evaporation, however, increased more than precipitation, resulting in a global soil-water deficit. 
A spectral analysis of the monthly mean precipitation simulated by the two scenarios suggests that changes in the state of the vegetation as an external forcing could affect the low-frequency modes of the precipitation distribution, and might reduce its low frequency variability in the tropics while increasing it in northern latitudes.

These results are based on a particular GCM and its land surface scheme which were externally forced by a monthly mean seasonal cycle of vegetation density and its related parameters. Additional experiments with more sophisticated interactive climate-vegetation models are certainly warranted.

Acknowledgment : We would like to thank the two anonymous reviewers for their valuable comments and suggestions. This research was funded by a NASA Earth Observing System Interdisciplinary Science Grant :" Biosphere-Atmosphere Interactions" and by NASA grant NAG5-3172 


\section{Figure Captions}

Plate $1:$ SiB2 biome distribution at 7.2 by 9.0 degrees resolution.

1: Broadleaf-evergreen trees (tropical forest), 2: Broadleaf-deciduous trees,

3: Mixed Broadleaf and needleleaf trees, 4: Needleleaf-evergreen trees,

5: Needleleaf-deciduous trees, 6: Broadleaf trees with groundcover,

7: Grasslands, 8: Wooded grasslands, 9: shrubs with bare soil,

10: Dwarf trees and shrubs (Tundra), 11: No vegetation: bare soil,

12: Agriculture.

Figure 1 (a) Seasonal variation of ndvi for the minimum (dashed),

average (thin solid) and maximum (thick solid) scenarios averaged over

the latitude band $(50.4 \mathrm{~N}-72 \mathrm{~N})$, (b) same as (a) but for tropics

(14.4 S - 14.4 N), (c) same as (a) but for all land, (d) Global distribution of

annual mean ndvi difference. Values are scaled up by 100 and shaded

areas represent ndvi differences larger than 10.

figure 2 : Mean differences between the maximum and minimum scenarios for

fpar (FP : dimensionless), carbon assimilation (AS: micromoles $/ \mathrm{m} 2 / \mathrm{s}$ ),

canopy conductance (CO: $\mathrm{mm} / \mathrm{s})$ and water stress (WS: dimensionless) averaged

over the last five years of each simulation for January and July and for

the tropics, northem latitudes and all land points. Values of fpar and water stress

were multiplied by 10 for plotting purpose. 
Figure 3 : Same as figure 2 except for the component of the surface energy budget, net shortwave radiation (SW), net longwave radiation (LW), canopy transpiration (CT), canopy interception (CI), ground evaporation (GE), ground interception (GI), canopy sensible heat (CS) and ground sensible heat (GS). All components are fluxes and are in Watt/m2.

Figure 4 : Seasonal cycle of surface air temperature difference $(K)$ between the maximum and minimum scenarios composite over the last five years of each simulation over the northern latitudes. Note that the maximum ndvi scenario resulted in peak temperature increase in Spring (March) and a maximum cooling in summer (July).

figure 5 : Zonally averaged surface air temperature difference $(\mathrm{K})$ over land . Differences are obtained from averages over the last five years of each simulation, for July ( thick dashed line), and January ( thick solid line) .

Figure 6 : Global distribution of annual mean surface temperature difference (maximum-minimum) in Kelvin, averaged over the last five years of each simulation. The three levels of shading show regions where the Student t-test value exceeds the 90\% (light), 95\% (dense), and 98\% (dark), respectively.

Figure 7 : Monthly mean difference (maximum - minimum) for the tropics and the northern latitude bands for a,b: rainfall rate ( $\mathrm{mm} / \mathrm{day}), \mathrm{c}, \mathrm{d}$ : water content as a fraction of 
saturation in the surface layer, e,f: water content fraction in the root zone layer (solid line) and deep soil layer (dashed line).

Figure 8 : Global changes in water content in the different water stores during the month of July. Differences are obtained using the last five years of each simulation (maximum-minimum) over all land and are in (mm); (CIS) : canopy interception store, (GIS) : gound interception store, (SLS) : surface layer store, (RLS) : root layer store, (DLS) : deep layer store .

Figure 9 : Time variation of total soil moisture in the three soil layers (m) during the course of the 15 years of model integration, for a: tropical latitudes and b: northern latitudes. Dashed lines correspond to the maximum ndvi scenario, and solid lines correspond to the minimum ndvi scenario.

Figure 10 : Power spectrum of the monthly mean rainfall rates ( $\mathrm{mm} /$ day) for the maximum ndvi scenario (thick solid curve) and minimum ndvi scenario (thick dashed curve). The thin solid and dotted lines correspond to the $95 \%$ confidence limit for the maximum and minimum scenarios,respectively; a: tropical latitudes and b: northern latitudes. 


\section{Table Captions}

Table 1 : Mean changes in fpar and albedo for tropical and northern latitude bands and for all land points resulting from changes in ndvi (maximum-minimum).

Albedo differences are based on avearges over the last five years of each run.

Table 2 : Same as in Table 1 but for canopy carbon assimilation and conductance.

Table 3 : Mean changes in surface air temperature for tropical and northern latidues bands and for all land points resulting from changes in ndvi (maximum - minimum). Diefferences are based on averages over the last five years. Values in parenthesis are mean temperatures ( C ) over the last five years for the minimum scenario ndvi case.

Table 4 : Mean changes in the hydrological cycle fluxes in ( $\mathrm{mm} / \mathrm{month})$ for tropical and northern latitude bands and for all land points resulting from changes in ndvi (maximum - minimum ). Differences are based on avearges over the last five years of each run. 


\section{a : SiB2 biome distribution}

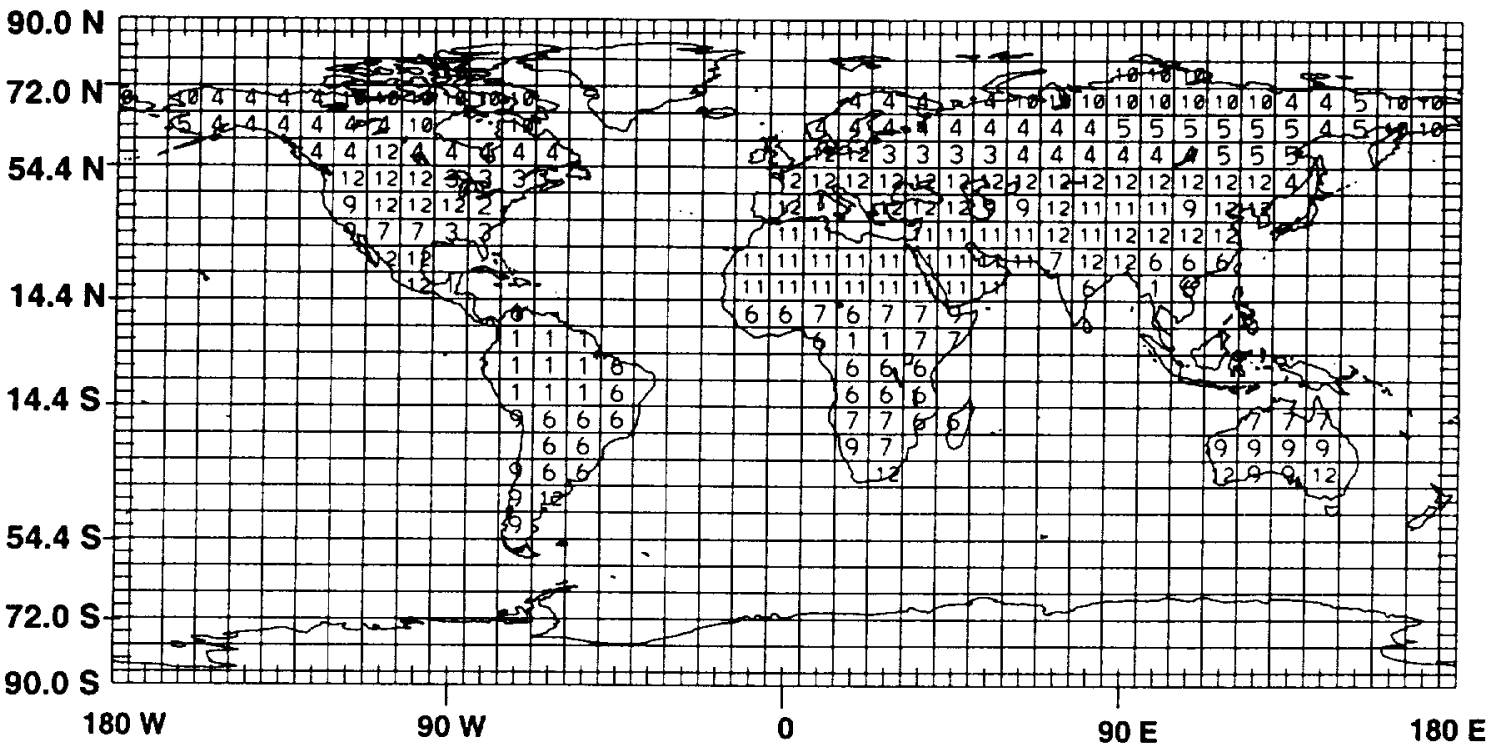

Plate 1 

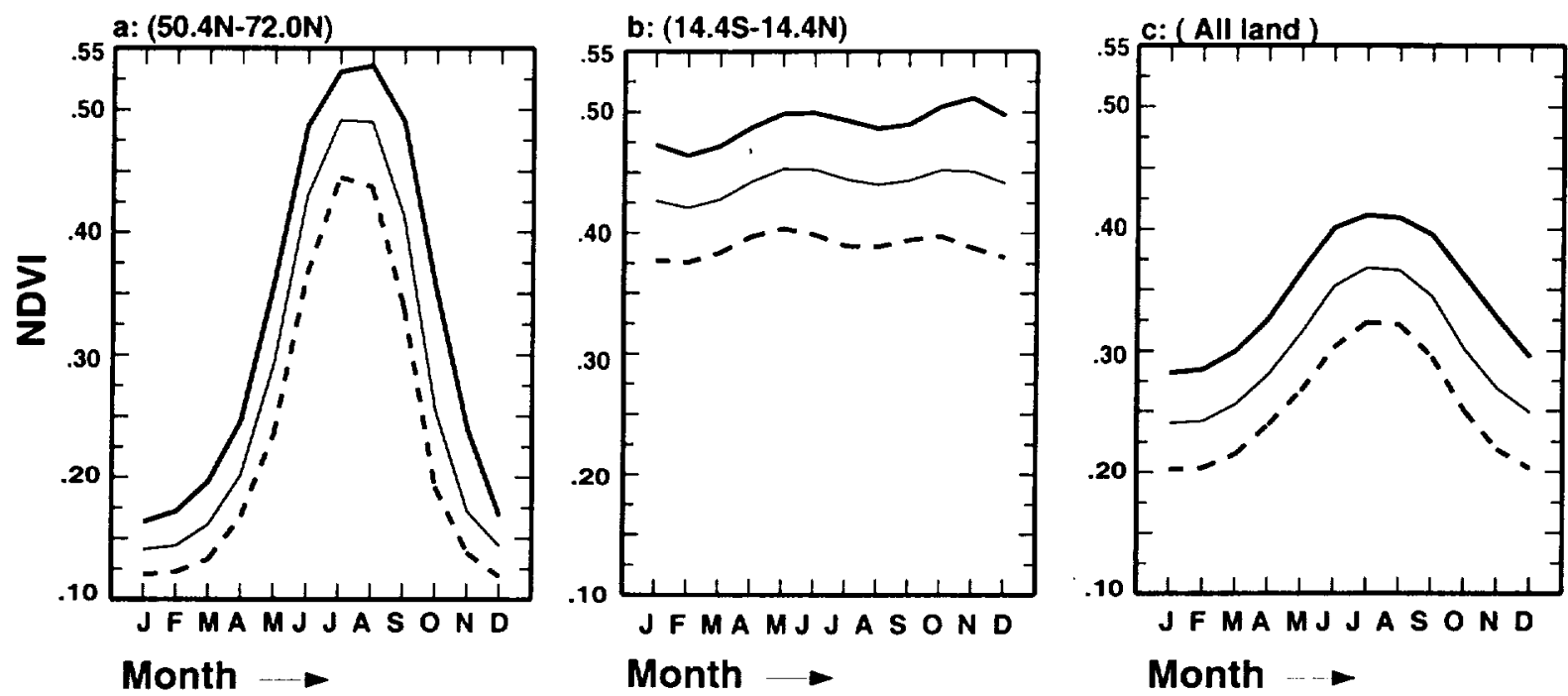

d: Annual mean ndvi difference

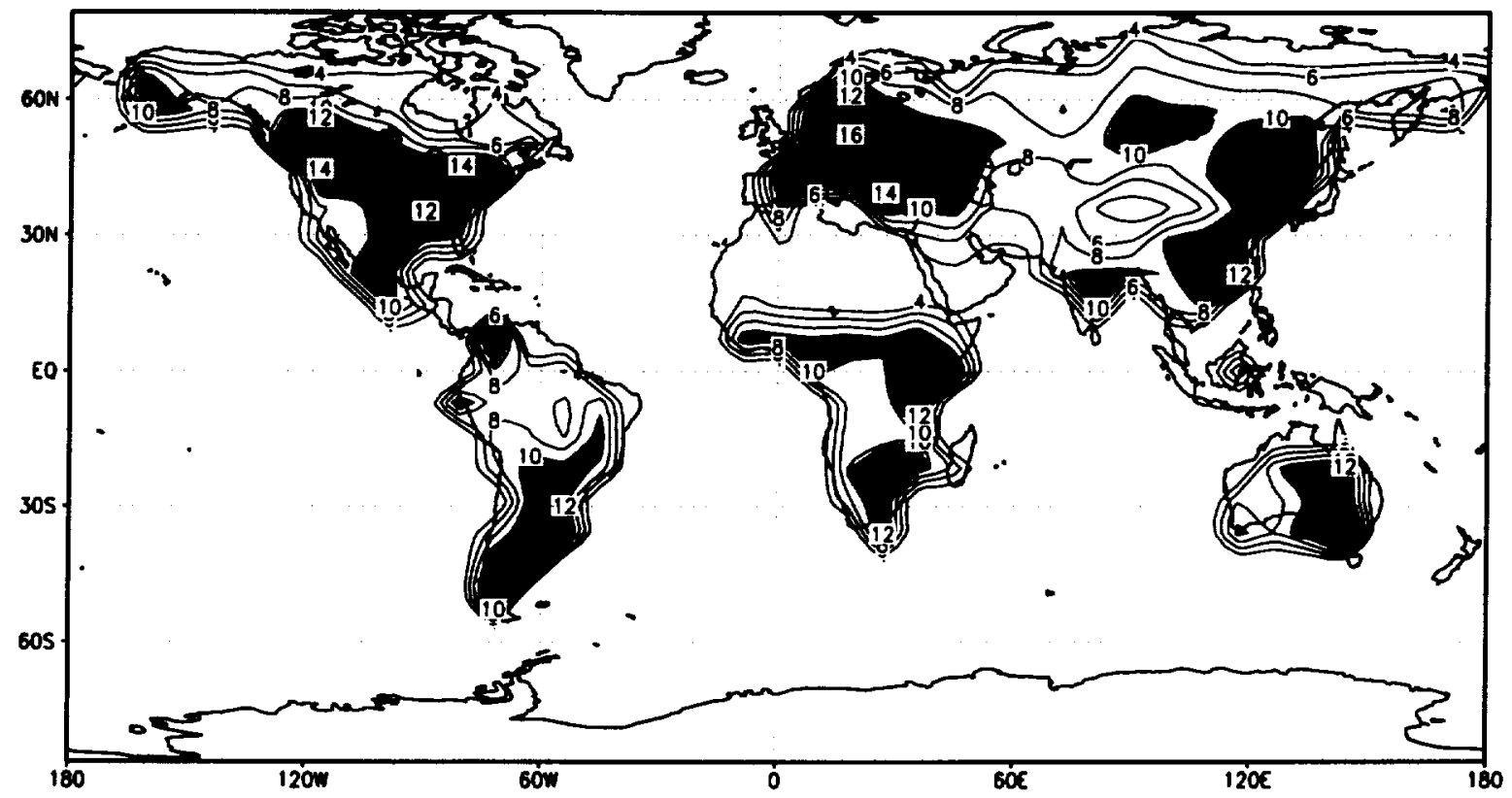

Fg I 

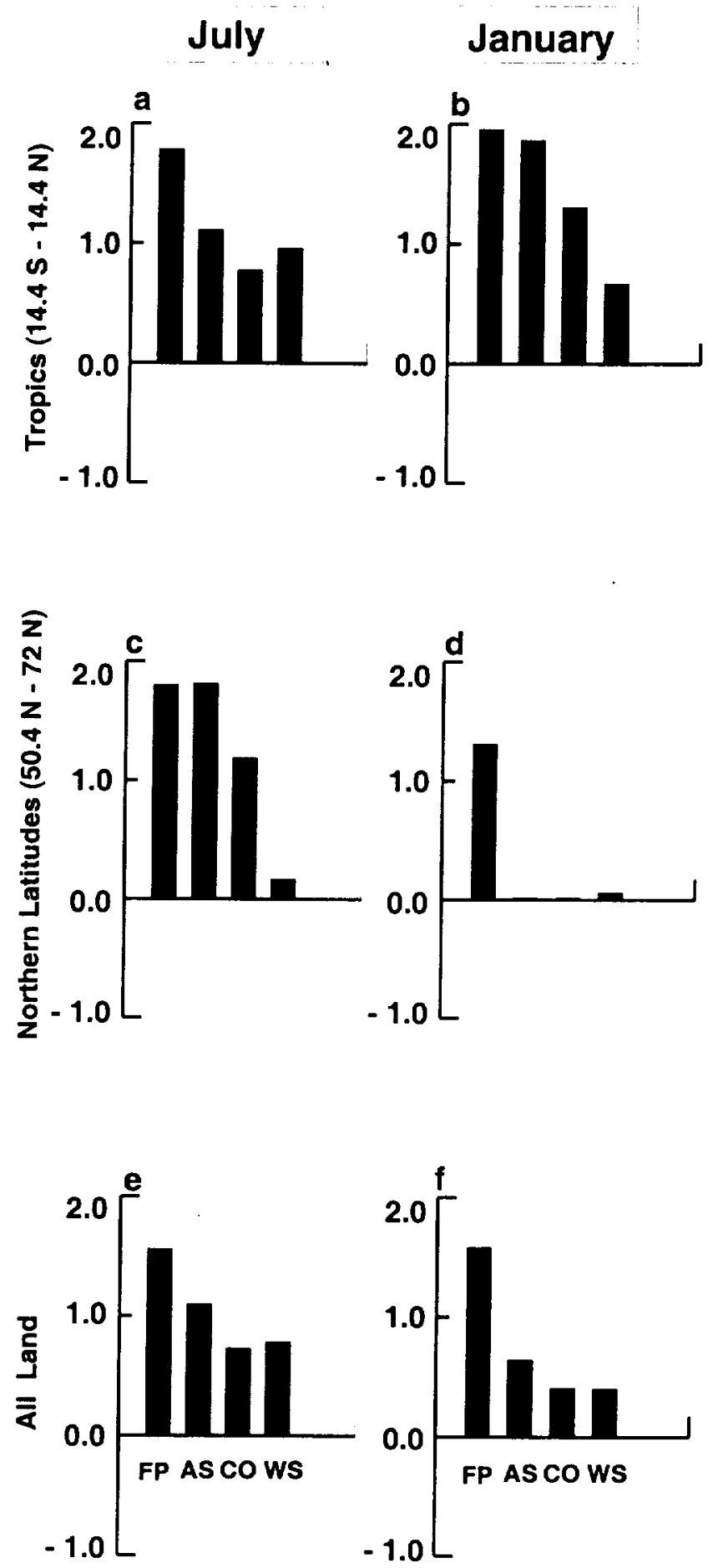

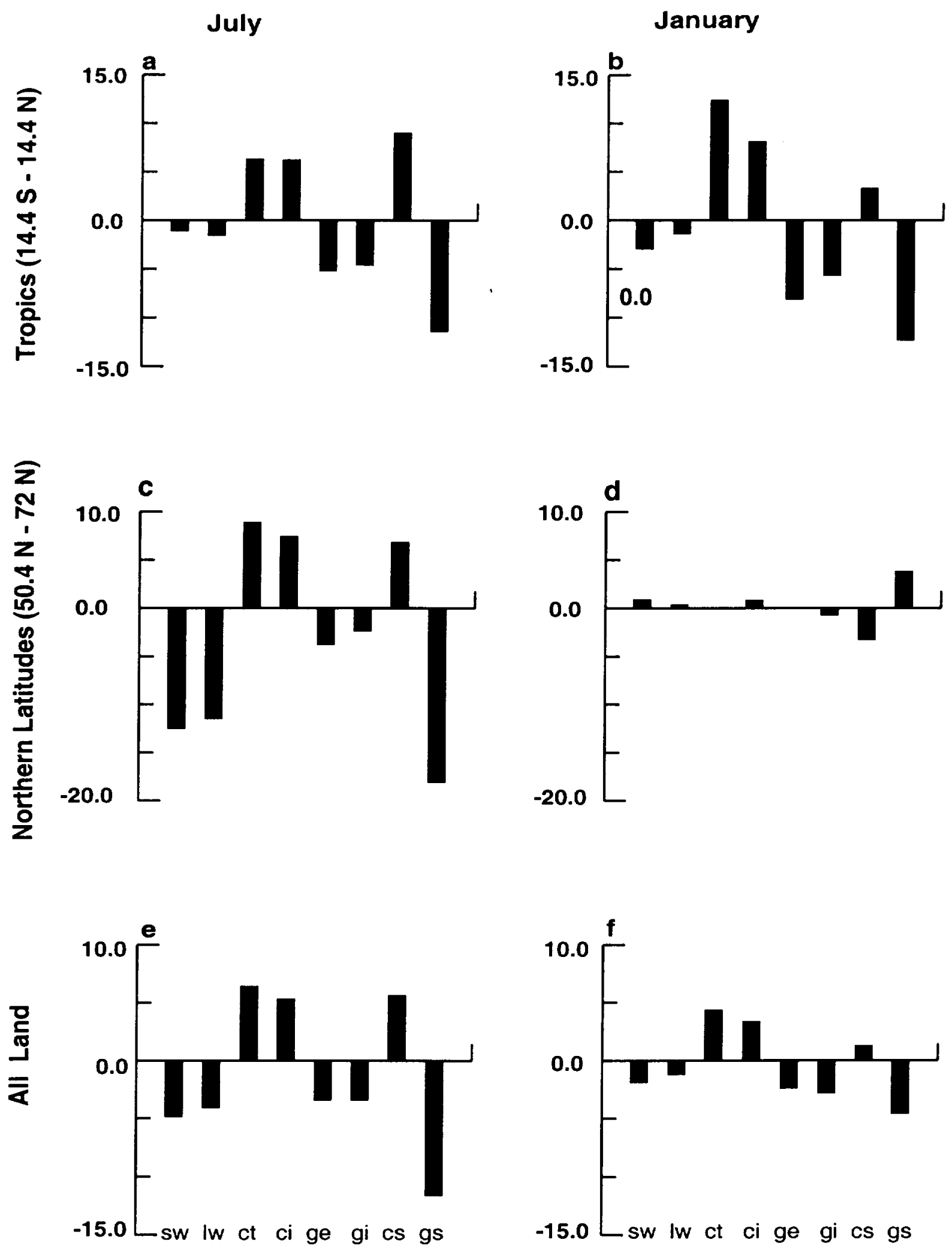


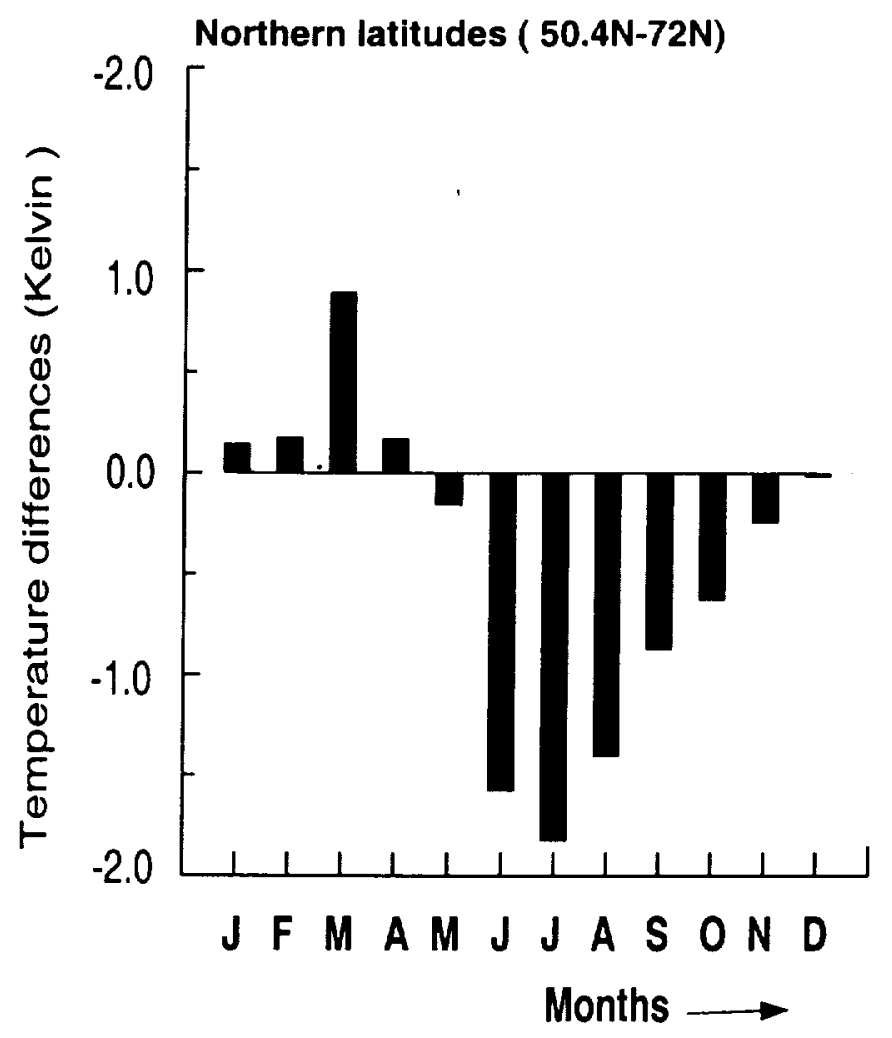




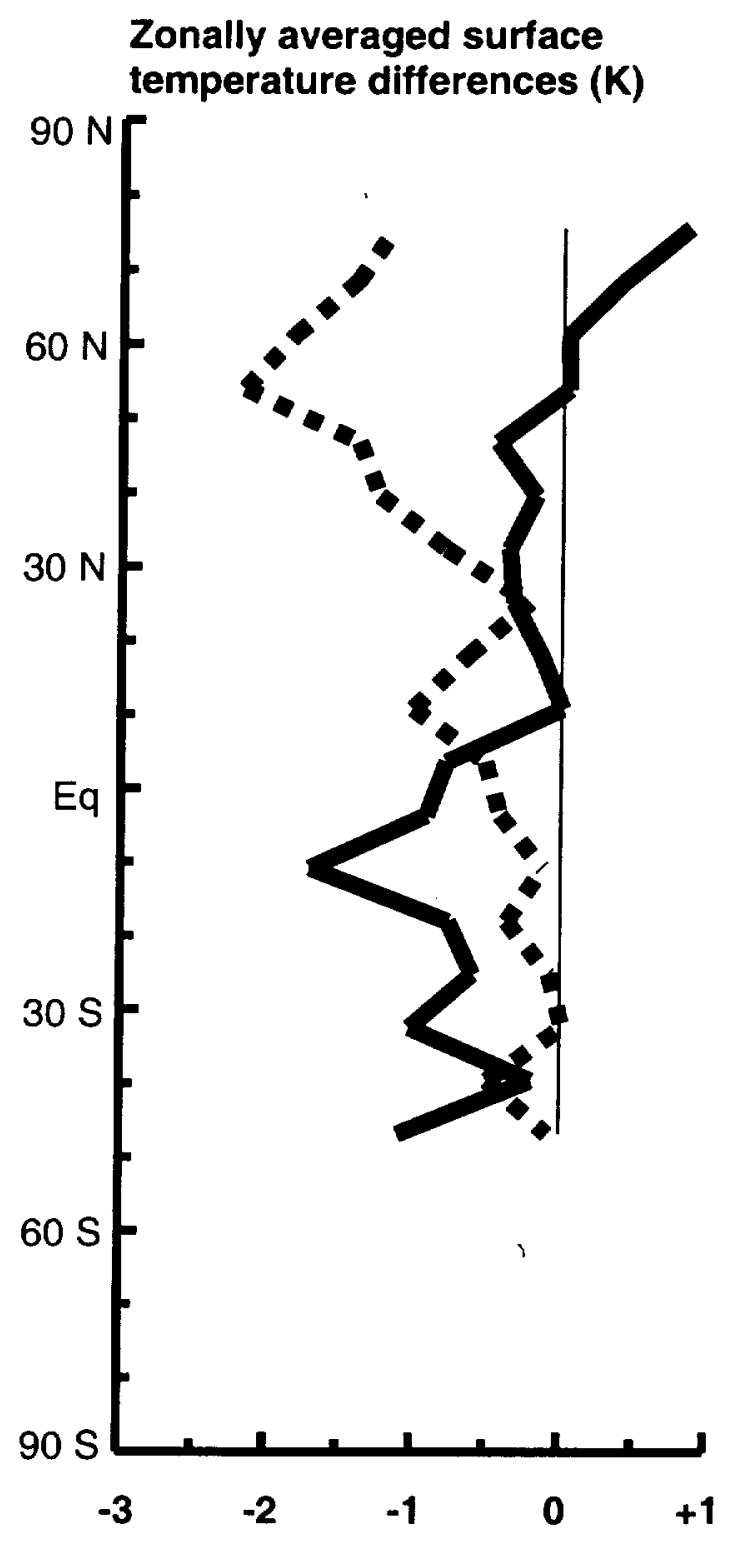




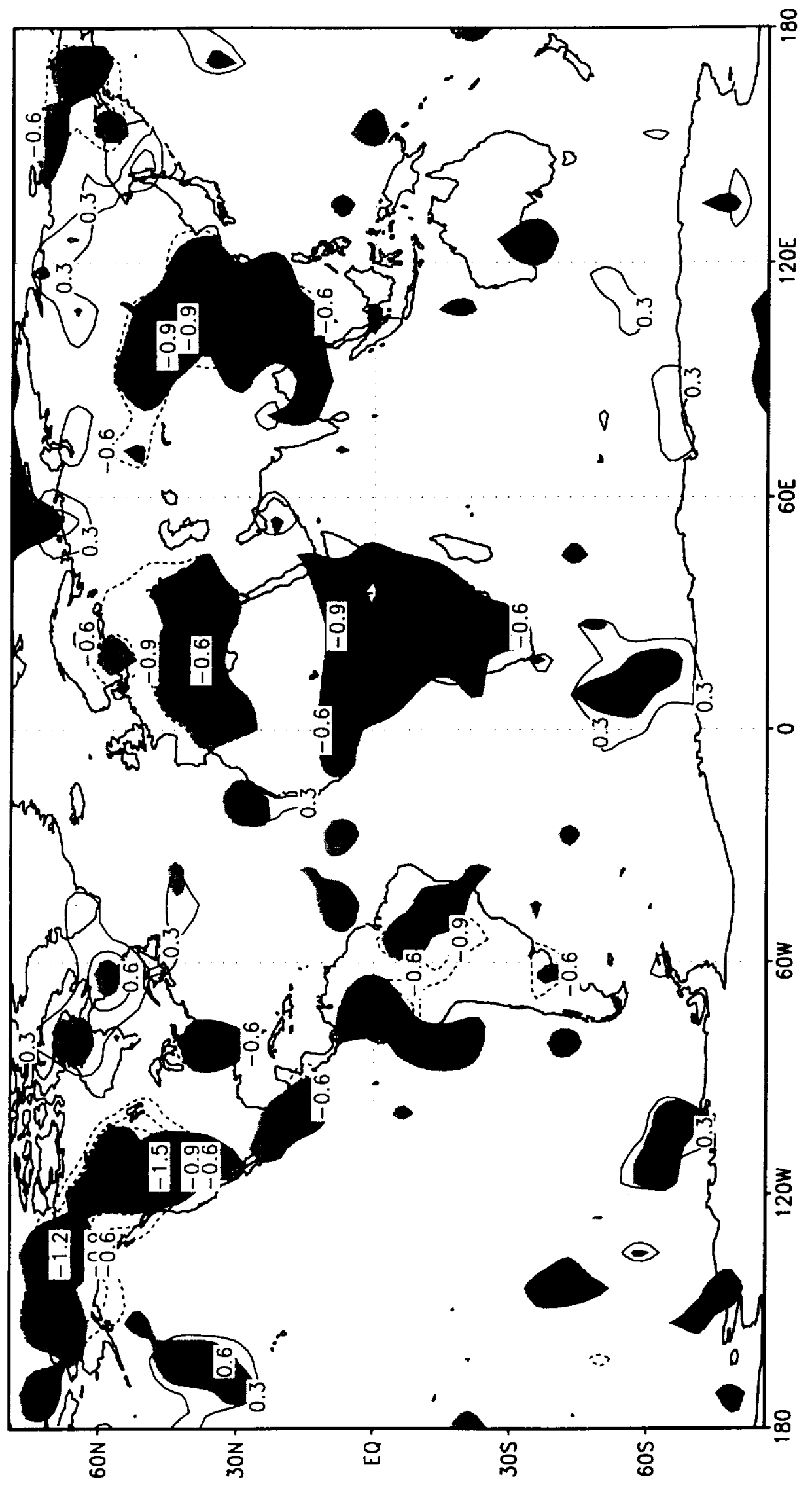



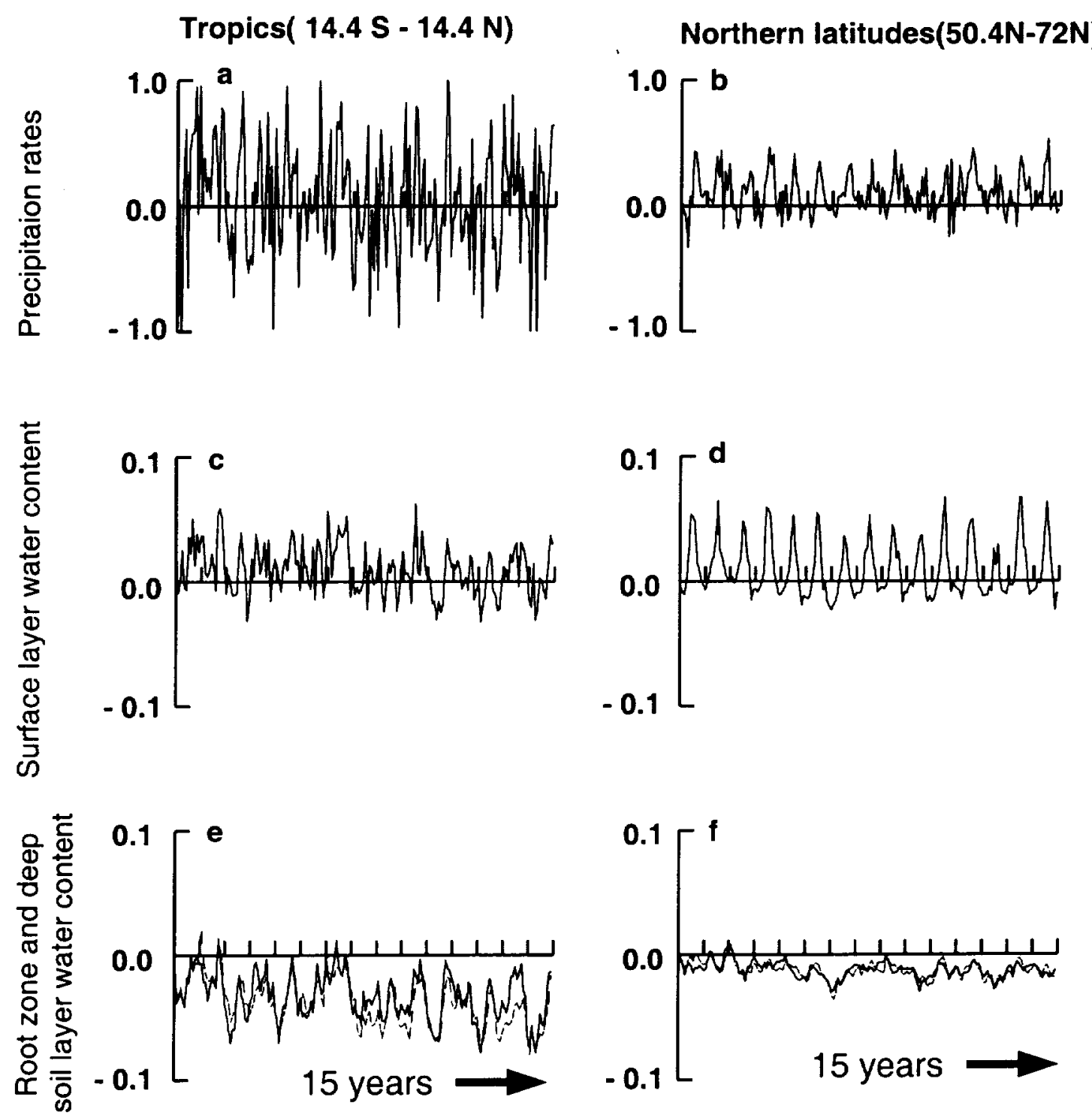


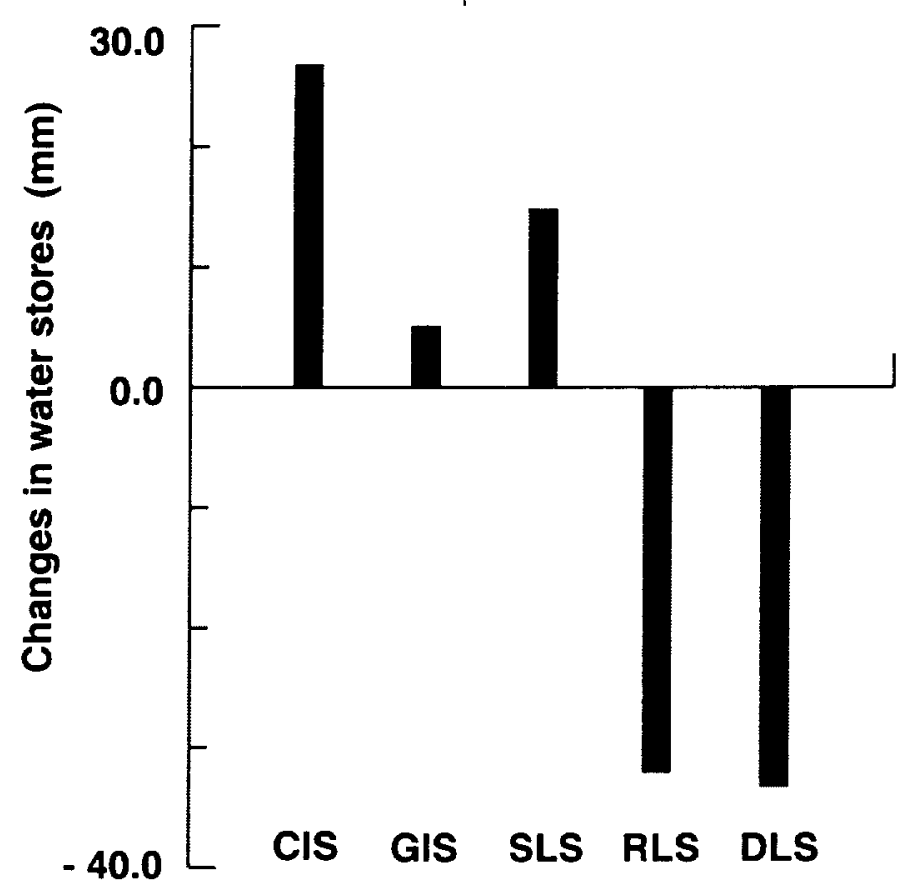



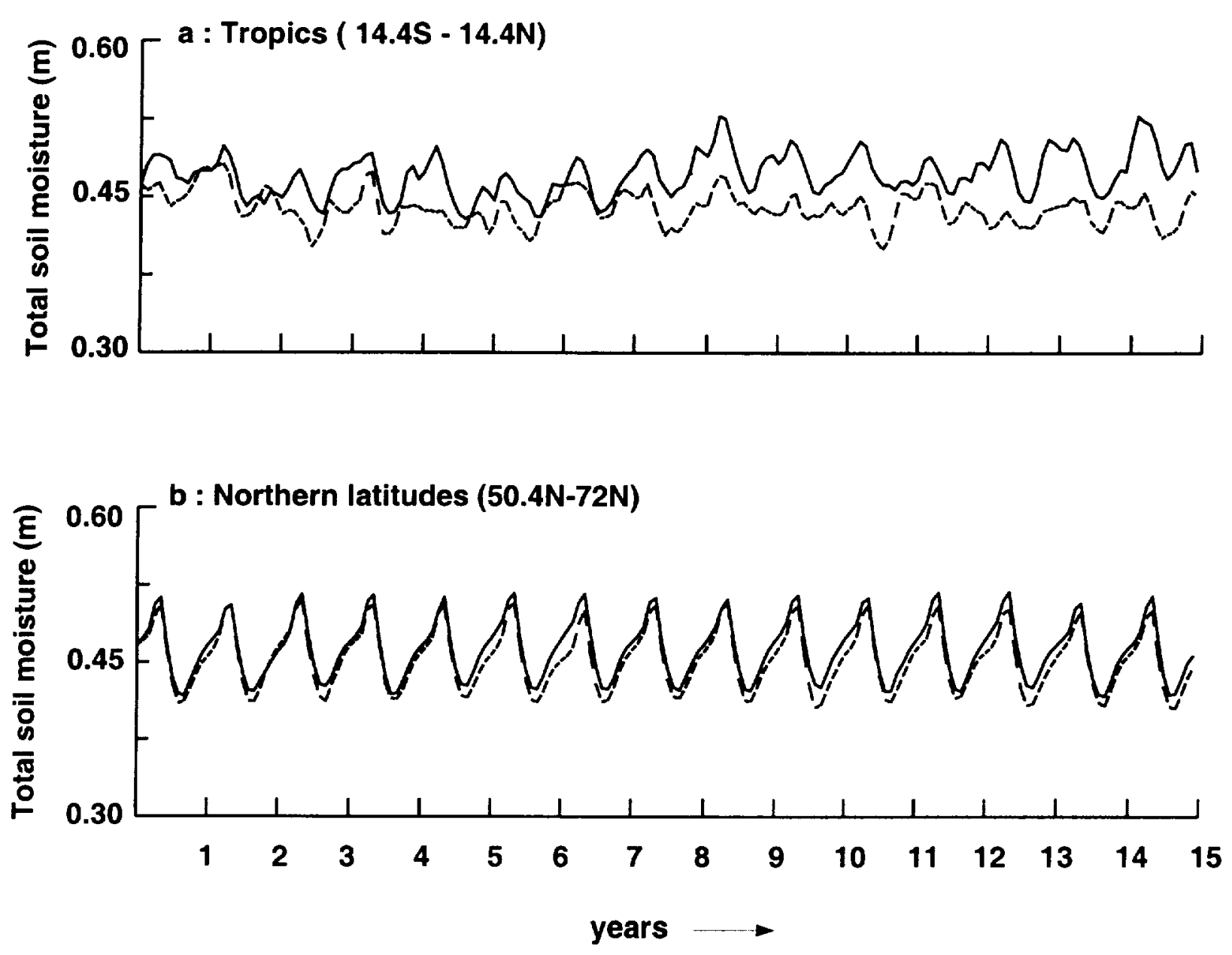

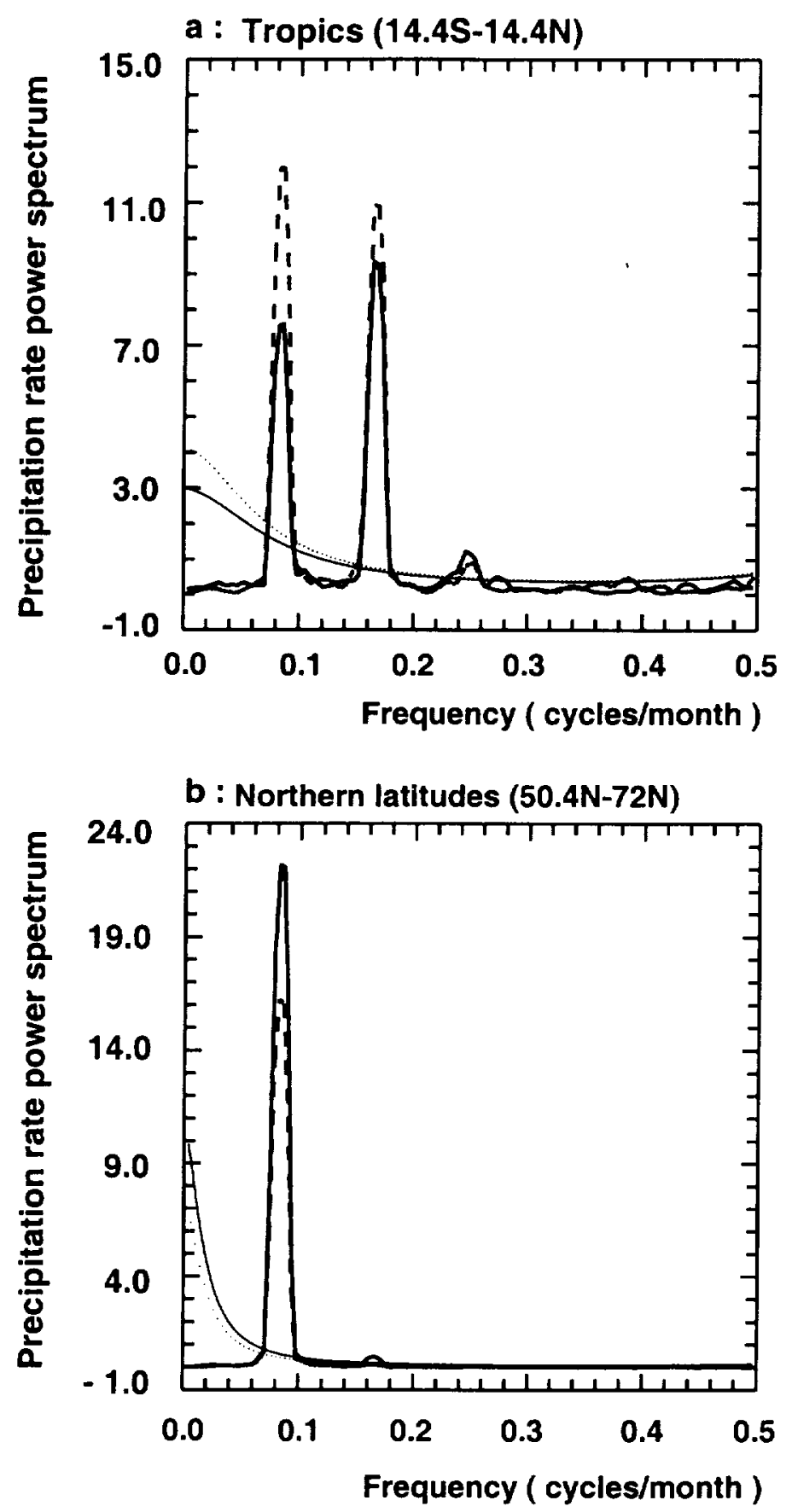
Table 1

\begin{tabular}{|c|c|c|c|c|c|}
\hline & $\begin{array}{l}\text { Mean fpar for } \\
\text { the minimum } \\
\text { ndvi case } \\
\text { (dimensionless) }\end{array}$ & $\begin{array}{l}\text { Relative change } \\
\text { in fpar } \\
\text { (max-min) } / \mathrm{min} \\
\text { (Percent) }\end{array}$ & $\begin{array}{l}\text { Mean albedo for } \\
\text { the minimum } \\
\text { ndvi case } \\
\text { (Dimensionless) }\end{array}$ & $\begin{array}{l}\text { Relative change } \\
\text { in albedo } \\
\text { (max-min) / min } \\
\text { (Percent) }\end{array}$ & \\
\hline \multirow{3}{*}{$\begin{array}{r}\text { July } \\
\text { January } \\
\text { Annual }\end{array}$} & 0.57 & 31.49 & 0.16 & 2.83 & \multirow{3}{*}{ 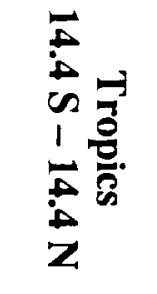 } \\
\hline & 0.54 & 36.06 & 0.15 & 5.35 & \\
\hline & 0.56 & 32.43 & 0.15 & 3.11 & \\
\hline \multirow{3}{*}{$\begin{array}{r}\text { July } \\
\text { January } \\
\text { Annual }\end{array}$} & 0.44 & 40.99 & 0.14 & -5.56 & \multirow{3}{*}{ 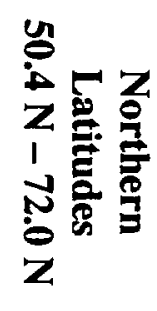 } \\
\hline & 0.24 & 54.99 & 0.41 & -9.44 & \\
\hline & 0.33 & 51.74 & 0.25 & -9.22 & \\
\hline \multirow{3}{*}{$\begin{array}{r}\text { July } \\
\text { January } \\
\text { Annual }\end{array}$} & 0.39 & 40.41 & 0.18 & 0.69 & \multirow{3}{*}{ 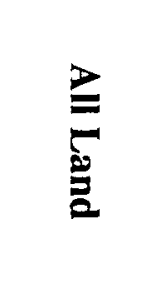 } \\
\hline & 0.29 & 54.86 & 0.26 & -2.65 & \\
\hline & 0.34 & 46.56 & 0.21 & -1.65 & \\
\hline
\end{tabular}


Table 2

\begin{tabular}{|c|c|c|c|c|c|}
\hline & $\begin{array}{l}\text { Mean assimilation } \\
\text { for the minimum } \\
\text { ndvi case } \\
\text { (micromoles } / \mathrm{m} 2 / \mathrm{s} \text { ) }\end{array}$ & $\begin{array}{l}\text { Relative change } \\
\text { in assimilation } \\
\text { (max-min) } / \mathrm{min} \\
\text { (Percent) }\end{array}$ & $\begin{array}{l}\text { Mean } \\
\text { conductance for } \\
\text { the minimum } \\
\text { ndvi case }(\mathrm{mm} / \mathrm{s})\end{array}$ & $\begin{array}{l}\text { Relative change } \\
\text { in conductance } \\
\text { (max-min) / min } \\
\text { (Percent) }\end{array}$ & . \\
\hline July & 4.03 & 27.65 & 1.65 & 47.27 & \multirow{3}{*}{ 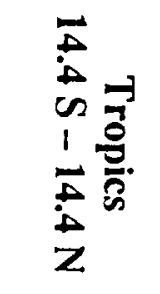 } \\
\hline \multirow{2}{*}{$\begin{array}{l}\text { January } \\
\text { Annual }\end{array}$} & 5.07 & 36.89 & 1.17 & 60.37 & \\
\hline & 4.87 & 31.40 & 2.07 & 50.72 & \\
\hline July & 3.44 & 52.57 & 1.81 & 65.75 & \multirow{3}{*}{ 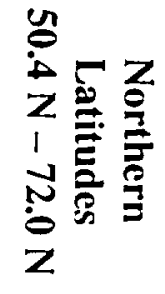 } \\
\hline \multirow{2}{*}{$\begin{array}{c}\text { January } \\
\text { Annual }\end{array}$} & 0.00 & N/A & 0.00 & N/A & \\
\hline & 1.26 & 57.63 & 0.66 & 75.76 & \\
\hline July & 2.88 & 38.36 & 1.29 & 56.59 & \multirow{3}{*}{$\geqq$} \\
\hline \multirow{2}{*}{$\begin{array}{c}\text { January } \\
\text { Annual }\end{array}$} & 1.56 & 41.38 & 0.62 & 66.13 & \\
\hline & 2.14 & 42.06 & 0.90 & 62.22 & \\
\hline
\end{tabular}


Table 3

\begin{tabular}{|r|c|c|c|}
\hline & Tropics & $\begin{array}{c}\text { Northern Latitudes } \\
\mathbf{5 0 . 4} \mathbf{~ N}-\mathbf{7 2 . 0} \mathbf{~}\end{array}$ & All Land \\
\hline \hline July & $-0.5(28.24)$ & $-1.8(24.87)$ & $-0.9(27.67)$ \\
\hline January & $-0.8(28.88)$ & $+0.2(-13.76)$ & $-0.4(11.16)$ \\
\hline Annual & $-0.8(29.28)$ & $-0.5(4.27)$ & $-0.5(19.58)$ \\
\hline
\end{tabular}


Table 4

\begin{tabular}{|c|c|c|c|c|}
\hline & $\begin{array}{l}\text { Evaporation } \\
\text { (mm/month) }\end{array}$ & $\begin{array}{l}\text { Precipitation } \\
\text { (mm/month) }\end{array}$ & $\begin{array}{c}\text { Runoff } \\
\text { (mm/month) }\end{array}$ & \\
\hline \multirow{3}{*}{$\begin{array}{r}\text { July } \\
\text { January } \\
\text { Annual }\end{array}$} & 2.8 & 2.5 & -4.5 & \multirow{3}{*}{ 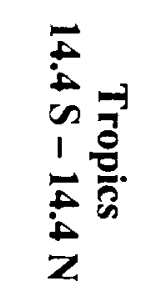 } \\
\hline & 7.2 & -6.2 & -3.4 & \\
\hline & 4.8 & 0.2 & -4.6 & \\
\hline \multirow{3}{*}{$\begin{array}{r}\text { July } \\
\text { January } \\
\text { Annual }\end{array}$} & 10.5 & 9.3 & -0.9 & \multirow{3}{*}{ 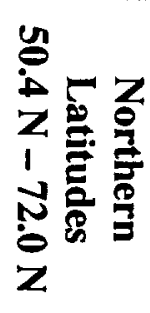 } \\
\hline & 0.2 & 1.8 & +0.5 & \\
\hline & 3.6 & 3.2 & -0.4 & \\
\hline \multirow{3}{*}{$\begin{array}{r}\text { July } \\
\text { January } \\
\text { Annual }\end{array}$} & 5.2 & 2.2 & -1.7 & \multirow{3}{*}{ 己 } \\
\hline & 2.7 & 0.3 & -0.1 & \\
\hline & 3.8 & 1.6 & -2.2 & \\
\hline
\end{tabular}




\section{References}

Bonan, G. B., 1997: Etfects of land use on the climate of the United States. Climatic Change, 37, 449-486.

Bonan, G. B., D. Pollard and S. L. Thompson, 1992: Effects of Boreal Forest Vegetation on Global Climate. Nature, 359, 716-718.

Bounoua, L., G. J. Collatz, P. J. Sellers, D. A. Randall, D. A. Dazlich, S. O. Los, J. A. Berry, I. Fung., C. J. Tucker, C. B. Field, and T. G. Jensen 1999 : Interactions Between vegetation and Climate: Radiative and Physiological effects of Doubled Atmospheric CO2. J. Climate, 12, 309-323.

Bounoua, L. and T. N. Krishnamurti, 1993a: Influence of soil moisture on Sahelian climate Prediction I. Meteorology and Atmospheric Physics, 52, 183-203.

Bounoua, L. and T. N. Krishnamurti. 1993b: Influence of soil moisture on Sahelian climate Prediction II. Meteorology and Atmospheric Physics, 52, 205-224.

Carson, D. J., A. J. Sangster, 1981: The influence of land-surface albedo and soil moisture on gerneral circulation model stimulation. In: Rutherford, I. D. (ed.) Research Activities in Atmopsheric and Oceanic Modelling. Numerical Experimentation Program Report No. 2, pp. 5.14-5.21.

Chahine, M. T., 1992: The hydrologic cycle and its influence on climate, Nature, 359, $373-380$.

Chapin, F. S., S. A. Zimov, G. R. Shaver, S. E. Hobbie, 1996: $\mathrm{CO}_{2}$ fluctuation at high latitudes. Nature, 383, 585-586.

Charney, J. G., 1975: Dynamics of deserts and drought in the Sahara. Quart. J. Roy. Meteor. Soc., 101, 193-202.

Charney, J. G., W. J. Quirk, S. H. Chow, J. Kornfield, 1977: A comparative study of the effects of albedo change on drought in semi-arid regions. J. Atmos. Sci., 34, 13661385. 
Chase, T. N., R. A. Pielke, Timothy G. F. Kittel, R. Nemani, and S. W. Running, 1996: Sensitivity of a general circulation model to global changes in leat area index. J. G. R., 101, 7393-7408.

Chervin, R. M., 1979: Response of the NCAR general circulation model to changed land surface albedo. Report of the JOC Study Convergence on Climate Models: Performance, Intercomparison and Sensitivity Studies. GARP Publ. Series, No. 212, Vol. 1, 563-581.

Chervin, R. M., S. H. Schneider, 1976a: A Study of the Response of NCAR GCM Climatological Statistics to Random Perturbations: Estimating Noise Levels. J. Atmos. Sci., 33, 391-404.

Collatz, G. J., L. Bounoua, S. O. Los, D. A. Randall, P. J. Sellers, I. Y. Fung, 1999: Influence of vegetation on the diurnal temperature range (in preparation).

Collatz, G.J., J.A. Berry, and J.S. Clark, 1998: Effects of climate and atmospheric CO2 partial pressure on the global distribution of $\mathrm{C} 4$ grasses: Present, past and future, Oecologia 114, 441-454.

Collatz, G. J., M. Ribas-Carbo, J. A. Berry, 1992: Coupled photosynthesis-stomatal conductance model for leaves of C4 plants. Australian Journal of Plant Physiology, 19, $519-538$.

Cowan, I.R. 1986: Economics of Carbon Fixation, In: Givnish, T.J. (Ed) On the economy of plant form and function. Cambridge University Press, Cambridge, UK, 133170.

Deardorff, J. W., 1972: Parameterization of the planetary boundary layer for use in general circulation models. Mon. Wea. Rev., 100, 83-106.

DeFries, R. S. and J. R. G. Townshend, 1994a: NDVI-derived land cover classification at global scales. International Journal of Remote Sensing. 15, 3567-3586. Special Issue on Global Data Sets. 
Dorman, J. L. and P. J. Sellers, 1989: A global climatology of albedo, roughness length and stomatal resistance for atmospheric general circulation models as represented by the simple biosphere model (SiB). J. Appl. Meteor., 28, 833-855.

Entekhabi, D., I. Rodriguez-Iturbe and R. L. Bras, 1992: Variability in large-scale water balance with landsurface-atmosphere interaction, Journal of Climate, 5(8), 798-813.

Fowler, L. D., D. A. Randall, and S. A. Rutledge, 1996: Liquid and ice cloud microphysics in the CSU general circulation model. Part I: Model description and simulated microphysical processes. J. Climate, 9, 489-529.

Fowler, L. D., and D. A. Randall, 1996a: Liquid and ice cloud mycrophysics in the CSU general circulation model. Part II: Impact on cloudiness, the earth's radiation budget, and the general circulation of the atmosphere. J. Climate, 9, 530-560.

Fowler, L. D., and D. A. Randall, 1996b: Liquid and ice cloud microphysics in the CSU general circulation model. Part III: Sensitivity to modeling assumptions, 561-586

Gash, J. H., J. S. Wallace, C. R. Lloyd, A. J. Dorman, M. V. K. Sivakumar, C. Renard, 1991: Measurements of evaporation from follow Sahelian savanah at start of the dry season. Quart. J. Roy. Meteor. Soc., 117, 716-749.

Hansen J., M. Sato, R. Ruedy, 1995: Long-term changes of the diurnal temperature cycle: implications about mechanisms of global climate change, Atmospheric Research, 37,175209.

Harshvardhan, R., D. A. Randall, T. G. Corsetti, 1987: A fast radiation parameterization for general circulation models. J. Geophys. Res., 92, 1009-1016. 
Henderson-Sellers, A., K. MuGuffie, and C. Gross, 1995: Sensitivity of global climate model simulations to increased stomatal resistance and $\mathrm{CO}_{2}$ increases. J. Climate, 8, 17381756.

Jensen, T. G., D. A. Dazlich, and D. A. Randall, 1995: A one-dimensional mixed layer ocean and sea ice model with prescribed oceanic heat transport", Colorado State University, Department of Atmospheric Science, Paper No. 593.

Karl, T. R., G. Kukla, V. N. Razuvayev, M. J. Changery, R. G. Quayle, R. R. Heim, Jr., D. R. Easterling, C. B. Fu, 1991: Global Warming: Evidence for asymmetric diurnal temperature change, Geophys. Res. Letters, 18, 2253-2256.

Keeling, C. D., J. F. S. Chin, T. P. Whorf, 1996: Increased activity of northern vegetation inferred from atmospheric $\mathrm{CO}_{2}$ measurements, Nature, 382, 146-149.

Laval, K., L. Picon, 1986: Effect of change of the surface albedo on the Sahel Climate. $J$. Atmos. Sci., 43, 2418-2429.

Los, S.O., 1998: Linkages between global vegetation and climate: An analysis based on NOAA advanced very high resolution radiometer data. $\mathrm{PhD}$. Thesis, Vrije Universiteit.

Manabe, S., 1975: A study of the interaction between the hydrological cycle and climate using a mathematical model of the atmosphere. Report on meeting on weather-food interactions, Massachusetts Institute of Technology, 21-45.

Myneni R. B., C. D. Keeling, C. J. Tucker, G. Asrar and R. R. Nemani. 1997: Increased plant growth in the northern high latitudes from 1981 to 1991. Nature, 386, 698-702.

Nobre, C. A., P. J. Sellers, and J. Shukla, 1991: Amazonian deforestation and regional climate change. J. Climate, 4, 957-987. 
Pielke, R. A., T. J. Lee, J. H. Copeland, J. L. Eastman, C. L. Ziegler, and C. A. Finley, 1997: Use of USGS-Provided Data to Improve Weather anc Climate Simulations. Ecol. Appl.., 7, 3-21.

Piper, S. C. and E. F. Stewart, 1996: A gridded global data set of daily temperature and precipitation for terrestrial biosphere modeling. Glob. Biogeochem. Cycles 10, 757-782.

Pollard, D. and S. L. Thompson, 1995: Use of land-surface-transfer scheme (LSX) in a global climate model: The response to doubling stomatal resistance. Global Planet. Change, 286, 1-32.

Randall, D. A., D.M. Pan, 1993: Implementation of the Arakawa-Schubert cumulus parameterization with a prognostic closure. Cumulus Parameterization, Meteor. Monogr.

No. 24, Amer. Meteor. Soc., 137-144.

Randall, D. A., D. A. Dazlich, C. Zhang, A. S. Denning, P. J. Sellers, C. J. Tucker, L. Bounoua, J. A. Berry, G. J. Collatz, C. B. Field, S. O. Los, C. O. Justice, and I. Fung, 1996: A revised land surface parameterization (SiB2) for GCMs. Part III: The greening of the Colorado State University General Circulation Model. J. Climate, 9, 738-763.

Rind, D., 1982: The influence of ground moisture conditions in North America on summer climate as modeled in the GISS GCM. Mon. Wea. Rev., 110, 1487-1494.

Rowell, D. P., C. Blondin, 1990: The influence of soil wetness distribution on shortrange rainfall forecasting in the West African Sahell. Quart. J. Roy. Meteor. Soc., 116, 1471-1485.

Rowntree, P. R., J. A. Bolton, 1983: Simulation of the atmospheric response to soil moisture anomalies over Europe. Quart. J. Roy Meteor. Soc., 109, 501-526.

Schwartz M. D., 1996: Examining the Spring Discontinuity in Daily Temperature Ranges. J. Climate, 9, 803-809. 
Scott, R., R. D. Koster, D. Entekhabi, M. J. Suarez, 1995: Effect of a canopy interception reservoir on hydrological persistence in a general circulation model. Journal of Climate, 8, 1917-1922.

Sellers, P. J., 1985: Canopy reflectance, photosynthesis and transpiration. Int. J. Remote Sens., 6, 1335-1372.

Sellers, P.J., 1987: Canopy reflectance, photosynthesis and transpiration. Part II: The role of biophysics in the linearity of their interdependence. Remote Sens. Environ., 21, 143-183.

Sellers, P. J., L. Bounoua, G. J. Collatz, D. A. Randall, D. A. Dazlich, S. O. Los, J. A. Berry, I. Fung, C. J. Tucker, C. B. Field, and T. G. Jensen, 1996a: Comparison of radiative and physiological effects of doubled atmospheric $\mathrm{C} 02$ on Climate. Science, 271, 1402-1406.

Sellers, P. J., D. A. Randall, G. J. Collatz, J. A. Berry, C. B. Field, D. A. Dazlich, C. Zhang, and L. Bounoua, 1996b: A revised land surface parameterization (SiB2) for atmospheric GCMs. Part I: Model formulation. J. Climate, 9, 676-705.

Sellers, P. J., S. O. Los, C. J. Tucker, C. O. Justice, D. A. Dazlich, G. J. Collatz, and D. A. Randall, 1996c: A revised land surface parameterization ( $\mathrm{SiB} 2)$ for atmospheric GCMs. Part II: The generation of global fields of terrestrial biophysical parameters from satellite data. J. Climate, 9, 706-737.

Sellers, P. J., J. A. Berry, G. J. Collatz, C. B. Field, and F. G. Hall, 1992: Canopy reflectance, photosynthesis and transpiration. Part III: A re-analysis using improved leaf models and a new canopy integration scheme. Remote Sens. Environ., 42, 187-216.

Shukla, J., and Y. Mintz, 1982: Influence of land surface evapotranspiration on the earth's climate. Science. 125, 1498-1501. 
Sud, Y. C., and A. Molod, 1988: A GCM simulation study of the influence of Sahara evapotranspiration and surface-albedo anomalies on July circulation and rainfall. Mon. Wea. Rev., 116, 2388-2400.

Sud, Y. C., and M. J. Fennessy, 1982: A study of the influence of surface albedo on July circulation in semi arid regions using the GIAS GCM. J. Climatol., 2, 105-125.

Sud, J. C., and W. E. Smith, 1984: Ensemble formulation of surface fluxes and improvement in evapotranspiration and cloud parameterization in a GCM. Bound.-Layer Meteor., 29, 185-210.

Sud, Y. C., G. K. Walker, J.-H. Kim, G. E. Liston, P. J. Sellers, W. K.-M. Lau, 1996 : Biogeophysical consequences of a Tropical deforestation Scenario: A GCM Simulation Study. J. Climate, 9, 3225-3247.

Walker, J., P. R. Rountree, 1977: The effect of soil moisture on circulation and rainfall in a tropical model. Quart. J. Roy. Meteor. Soc., 103, 29-46.

Xue, Y., M. J. Fennessy, and P. J. Sellers: Impact of Vegetation Properties on U.S. Summer Weather Prediction. J. Geophys. Res., 101, 7419-7430.

Xue, Y. K., and J. Shukla, 1993: The influence of land surface properties on Sahel climate. Part I: Desertification. J. Climate, 6, 2232-2245.

Yeh, T. C., R. T. Wetherland, S. Manabe, 1984: The effect of soil moisture on the shortterm climate and hydrology change - A numerical experiment. Mon. Wea. Rev., 112, 474490. 